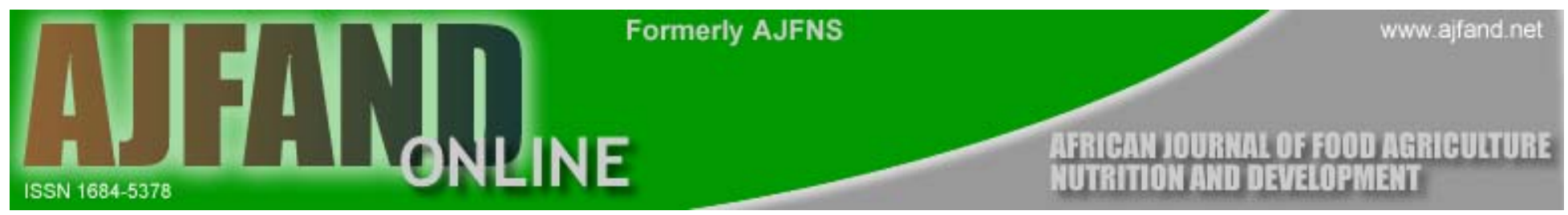

PEER REVIEWED ARTICLE No 3

\title{
A FRAMEWORK FOR EVALUATING FOOD SECURITY AND NUTRITION MONITORING SYSTEMS
}

Suresh B. * and A. Ergeneman

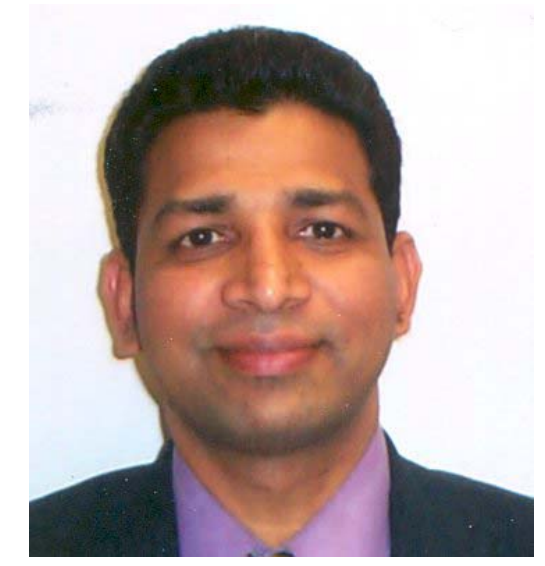

BABU SURESH

*Corresponding author: International Food Policy Research Institute, $2033 \mathrm{~K}$ Street, NW, Washington DC, 20006, e-mail: S.Babu@cgiar.org, phone: (202) 862-5618, fax: (202) 467-4439. 


\begin{abstract}
Identifying cost and time-efficient approaches to food security and nutrition monitoring programs is fundamental to increasing the utility and sustainability. Food security and nutrition monitoring systems should be periodically evaluated to ensure that their objectives are met, and re-oriented towards the changing information needs for food policy interventions. In meeting these challenges, the role of continued evaluation of food security monitoring systems - for their impact on food security decision-making - cannot be overemphasized. The linkage between the information generated by these systems, planning and policy processes to improve food security remains weak in several sub-Saharan African countries. This paper aims at developing a framework for evaluating food security and nutrition monitoring systems. Among the criteria used for evaluation are the capacity for data processing, analysis and, reporting, timely generation of information, commitment of decision makers and cost-effectiveness. Using this framework, the paper evaluates the National Early Warning System (NEWS) and the Famine Early Warning System (FEWS) programs in Uganda, to gain useful lessons for other countries in sub-Saharan Africa. A majority of food security monitoring systems continues to be based on macro-level information and operated at the national level. Future challenges in addressing household food security will require devolution of the process of food security monitoring and intervention systems to decentralized levels. The authors also find that a sound food security and nutrition monitoring system is simple, user-driven and has the commitment of relevant decision-makers, who will use the information in planning and policy design. The paper stresses that frequent evaluation of the methods and systems of monitoring food security is essential for sustaining the commitment of decisionmakers. Also, ongoing assessments will facilitate existing monitoring systems to develop into ones that encompass the sphere of livelihood security. The use of the livelihood approach in food security monitoring in turn will support preventive and proactive solutions, rather than curative approaches to food insecurity.
\end{abstract}

Keywords: Early warning, food security, nutrition, monitoring, evaluation

\title{
FRENCH
}

RÉSUMÉ

Il est fondamental d'identifier des coûts et des approches rentables permettant de contrôler la sécurité alimentaire et la nutrition en vue d'accrô̂tre l'utilité et la viabilité des programmes y relatifs. Les systèmes de contrôle de la sécurité alimentaire et de la nutrition devraient être périodiquement évalués afin d'assurer que leurs objectifs sont atteints et réorientés vers les besoins changeants en informations pour des interventions de politique alimentaire. Le lien entre les informations générées par ces systèmes et les processus de planification et d'ordre politique pour améliorer la 
sécurité alimentaire demeure faible dans de nombreux pays de l'Afrique subsaharienne. Le présent exposé met au point un cadre permettant d'évaluer les systèmes de contrôle de la sécurité alimentaire et de la nutrition. Parmi les critères utilisés dans l'évaluation figurent la capacité de traiter les données, l'analyse et la présentation des rapports, la production d'informations à temps, l'engagement des décideurs et la rentabilité. En utilisant ce cadre, cet exposé évalue les programmes de "Système national d'alerte avancée " et de Système national d'alerte rapide en cas de famine" en Ouganda afin d'en tirer des leçons utiles pour d'autres pays de l'Afrique subsaharienne. Les auteurs pensent qu'un système fiable de contrôle de la sécurité alimentaire et de la nutrition est simple et orienté vers l'utilisateur, et qu'il a l'engagement des décideurs concernés qui utiliseront ces informations lors de la planification et la conception de la politique sectorielle. Cet exposé souligne qu'une l'évaluation fréquente des méthodes et des systèmes de contrôle de la sécurité alimentaire est essentielle pour sous-tendre l'engagement des décideurs. En outre, des évaluations continues faciliteront les systèmes de contrôle qui sont déjà en place pour qu'ils deviennent des systèmes qui englobent la sphère de la sécurité du bétail. L'utilisation de l'approche relative au bétail dans le contrôle de la sécurité alimentaire appuiera des solutions préventives et dynamiques plutôt que des approches curatives en cas d'insécurité alimentaire.

Mots-clés: Alerte rapide, sécurité alimentaire, nutrition, contrôle, évaluation 


\section{INTRODUCTION}

The main objective of an early warning system is to monitor food security and nutritional status so to inform decision makers of impending food shortages at national and local levels. The response that an early warning system triggers is an important indicator of its success. The appropriateness of this response, in turn, depends on the links between the information generated by the system and the policy making process. This linkage remains weak in several sub-Saharan African countries. The recent food shortages experienced in Southern Africa and countries like Sudan and Ethiopia, are partly due to the failure by governments and international organizations to take public action of ensuring food security despite the presence of early warning systems in the countries [1, 2]. This is partly because food security monitoring systems, which are mostly established by external or donor funding, have not been fully integrated into the decision making processes of the government. Even though there has been limited analysis on the impact of monitoring systems on food security decision making, there is increasing interest on the part of African policy makers to improve the use of information provided by these systems. The nature and role of food security monitoring systems in meeting the information needs required by decision making processes vary, depending on the type and objective of these systems. However, a carefully outlined conceptual framework allows us to evaluate the performance of food security monitoring systems, and helps us move towards re-linking them to the policy making process.

Few attempts have been made to define the criteria needed for understanding the impact of the monitoring systems [3]. More importantly, there has not been any systematic evaluation of the role of monitoring systems in the decision making process. Continuous evaluation of the benefits of food security monitoring systems is necessary to ensure sustainability and allow them to alleviate food insecurity. More work needs to be done in assessing the operational aspects of food security monitoring systems. The quality and accuracy of data, appropriateness of data processing procedures, effectiveness of information disseminated, and its use for planning and policymaking purposes all need to be assessed. Such evaluations will re-orient food security monitoring systems towards the changing needs of its clients.

This paper develops a framework for evaluating food security and nutrition monitoring systems in sub-Saharan Africa. Using Uganda as a case study, it evaluates the National Early Warning System (NEWS) and the Famine Early Warning System (FEWS) in order to gain useful lessons for other countries in sub-Saharan Africa.

NEWS are generally implemented by the governments with the help of external donors and executing agencies, such as the Food and Agricultural Organization (FAO) of the United Nations (UN) or the United States Agency for International Development (USAID), and focus on monitoring food security at the national level. FEWS on the 
other hand are initiated and implemented by external agencies independently or in collaboration with the host country governments. They monitor food needs of the vulnerable population to prevent famine-related disasters $[4,5]$.

The Ugandan case study presented in this paper is based on a historical review of patterns of food security monitoring - on personal interviews with program managers of the monitoring systems, - and users of information in government and non-government organizations. The authors have done their best to reflect the changing nature of NEWS and FEWS over the years and that the issues identified in this paper remain valid.

The paper is organized as follows: First, we provide a conceptual framework for evaluating food security and nutrition monitoring systems. Next, based on this framework, the two parallel systems of food security monitoring in Uganda are evaluated. Consequently, lessons are drawn from these systems in designing and modifying food security monitoring systems to maximize information generation capacity to use in alleviating food insecurity. Finally, concluding remarks are presented in the last section.

\section{A Conceptual Framework for Evaluating Food Security Monitoring Systems}

Periodic monitoring of household food security and nutritional status is fundamental to generating adequate information on the its state, as well as the factors that influence it. The information collected through monitoring systems is a key ingredient for designing appropriate actions that will improve the food security and nutritional status of households. It is also important to assess the impact of these interventions with regard to improvements in food security and nutrition. Thus, food security and nutrition monitoring is defined as a process of monitoring, analysis, and interpretation of indicators and causal factors associated with household food security and nutrition, in order to make appropriate decisions that will lead to effective interventions to improve the food security and nutritional status of the population.

Lack of evaluations on the performance of food security and nutrition monitoring systems has been frequently suggested as the reason for the unsustainable nature of monitoring systems, which continue to be heavily donor-driven and dependent on external aid and technical assistance [6]. Monitoring systems should be evaluated on two levels: first, the performance of monitoring systems should be examined to determine the quality of information and whether it meets the information needs of users; second, the impact of information on policy decisions should be measured.

A sound food security and nutrition monitoring system is simple, user-driven, based on existing institutional structures (which increases the capacity for analysis and interpretation) and has the commitment of relevant decision makers who will use the information in planning and policy design. Tracking the deviations in implementing food security monitoring systems from these criteria helps to re-orient their activities towards the ultimate goal of forming informed food security decisions. 
Figure 1 lays out a conceptual framework for evaluating food security and nutrition monitoring systems. We view this evaluation as a cyclic one, with the criteria used to evaluate the performance of the monitoring systems presented in the circles on the periphery.

\section{The Criteria}

A fundamental factor that determines the sustainability of food security monitoring systems is the user-driven nature of the objectives towards which information is generated. Operational linkages between the monitoring system and the institutions using the generated information need to be in place for the system to be successful in triggering appropriate policy response $[7,8]$.

The quality of data and the speed with which it is generated is determined by the simplicity of the instruments used for gathering information. The use of existing infrastructure for collecting and compiling information has proven to be more successful, than the creation of new institutional structures for purposes of food security monitoring. Early warning systems can [and should] utilize traditional methods used by local communities for early warning purposes [9]. 


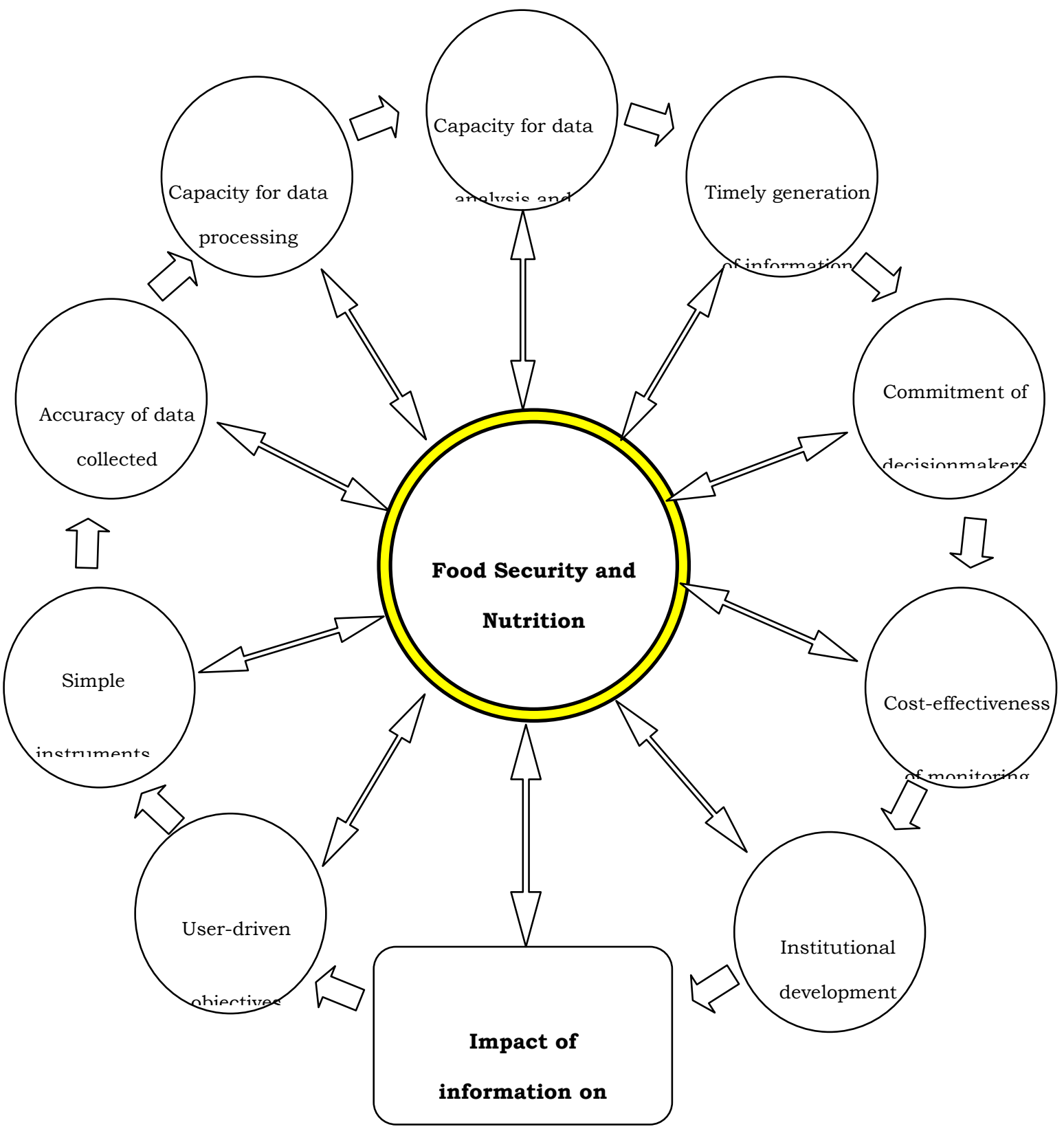

Figure 1. A conceptual framework for evaluating food security monitoring systems. 
Early warning systems should be evaluated on the accuracy of the data they produce as well as their capacity for data processing, analysis and interpretation. It is important that the information produced arrives in a timely fashion, giving decision makers enough lead way to produce the necessary policy responses. The same decision makers should be committed to using the data produced by these systems.

The cost of information generated should be weighed against the benefits of policy impact. Even though it is generally argued that such benefits are not readily quantifiable, one approach is to document the use of information from food security and nutrition monitoring systems, for various planning and policy making purposes on a case-by-case basis, and estimating cost-savings compared to generating the information separately. Even though the donors frequently raise the cost of food security and nutrition monitoring as a concern, very few attempts have been made to measure the actual costs and benefits of these systems. Empirical evidence from Malawi indicates that the internal rate of return to food security and nutrition monitoring ranges from 66 to 75 percent [10]. Another study shows that every dollar spent on mitigation saves approximately $\$ 4-10$ in recovery costs [11].

It is conceivable that donor agencies use part of the information collected by monitoring systems in their planning exercises and save donor resources, that would otherwise go towards data collection. Such benefits are over and above the benefits of information for which the monitoring system were originally intended. Furthermore, transparency in the use and sharing of data will enable faster response to food emergencies and limit the replication of data collection efforts [12].

Food security monitoring should eventually lead to institutional development, so that the information generated can be effectively used in decision making. Past experiences in food security monitoring systems indicate that there is a tendency towards using shortterm technical assistance in generating data from the field. Even with long-term projects, such as the ones implemented by FAO, there have not been adequate resources to develop institutional and human capacity to sustain and justify the existence of monitoring systems.

Monitoring the use of information in designing policies and intervention programs and evaluating the impact on policy decisions is important for identifying new channels for information dissemination. Information obtained from evaluating the benefits of monitoring systems in influencing policies can be a useful instrument for raising resources and support for sustaining them. Monitoring and evaluation of the impact of the output from monitoring systems in influencing policy decisions requires constant follow up of the flow of information and the documentation of this information, at various stages of decision making. This requires special efforts on the part of the monitoring systems' program managers. The benefits of such documentation, however, outweigh the time and cost involved. 


\section{FOOD SECURITY MONITORING SYSTEMS AND THE PROCESS OF DECISION MAKING}

\section{- A Ugandan Case Study}

Food insecurity continues to be a major development concern in Uganda despite the country's well-endowed natural resource base and bi-annual rainfall. It is important to ensure that all households have the access and ability to obtain minimum levels of food security and fulfill their nutritional needs - particularly in the most vulnerable groups that live in the chronically food insecure regions of the country or for those who reside in war-affected districts. Monitoring changes of food availability in areas affected by drought along with household coping strategies is useful for designing intervention strategies that are more decentralized and food security-oriented rather than famineoriented [13]. Accomplishing these goals requires continued monitoring, analysis and implementation of appropriate food security policies and programs. Adequate information on food availability and accessibility in various parts of the country is fundamental for designing intervention programs.

This section uses the case study of the early warning systems in Uganda to evaluate the performance of food security monitoring, and the process of information generation used for decision making in the food and agricultural sectors. Understanding the flow of information from the field to the decisionmaking authorities requires identifying the players involved and their role in the process of data collection, processing, analysis and dissemination.

Although achieving food security for all Ugandans is given a high priority by the government and the donors, investments towards identifying the food as insecure have not been adequately realized. Further, there is a lack of co-ordination in the efforts by the donor community and the government in information generation, and in its use for programming and policy planning activities. The diverse nature of information on the food security situation obtained from separate sources, leads to individual organizations designing their own strategies for solving the problem of food emergencies. Although they are well intended, these strategies often tend to conflict with each other and with the governments as well [14].

Along with several organizations engaged in food security, early warning and vulnerability assessment in Uganda, two major systems of information generation and dissemination are in operation for meeting food security and nutrition information needs: the National Early Warning System, implemented by the Ministry of Agriculture, Animal Industry and Fisheries (MAAIF), and the Famine Early Warning System, initiated and funded through USAID. While designed for specific purposes, due to the lack of sufficient cooperation and collaboration, these systems seem to compete for the same information sources and meet the needs of similar user groups. The current institutional arrangements of existing monitoring systems have not been successful in strengthening the impact of information used in the food security decision making processes. Given the 
limited in-country capacity for early warning of impending food shortages and related analysis, the existence of parallel systems of monitoring food security reduces the effectiveness of what is already available. This also gives mixed messages to those involved in food security issues on the earnestness of the government and donors in tackling the chronic food insecurity facing different parts of the country. In this paper, we will evaluate these systems of information generation and identify the major constraints in their institutional interaction in achieving the goals of informed food security decision making, within and outside the government. An added objective of the case study is to compare and contrast the operational and sustainability challenges faced by the two systems to shed light on the role of donors in enhancing the process of informed decision making.

\section{National Early Warning System (NEWS)}

Food security monitoring began in Uganda in July 1991, with the establishment of the National Early Warning and Food Information Unit in the Ministry of Agriculture, Animal Industry and Fisheries (MAAIF). The unit was created to improve early warning of food deficit problems in the country in order to provide vital information on the food situation to government, donors and non-governmental organizations. NEWS was established under the Inter-Governmental Authority on Development's (IGAD) Regional Early Warning and Food Information System Project, which has initiated National Early Warning Units in seven other countries in the region ${ }^{1}$. FAO provided technical assistance with financial support from the Italian Government in the first phase of the project (1990 - 1994).

The main functions of NEWS included: "... collecting, analyzing and interpreting crop, livestock, and agro-meteorological data, early forecasting of the main food crops production situation, identifying surplus and deficit areas to guide seasonal marketing operations; carrying out pre- and post-harvest crops assessments; collaborating with other government and non-governmental organizations and institutions to generate appropriate early warning information and networking with regional and international early warning centers to foster information exchange and use" [15].

The components of the NEWS project included periodic updates regarding growing conditions for the main food crops, such as cereals, pulses, oilseeds, root crops and plantains in order to forecast the likely crop yield and output. Weather forecasting was done in consultation and collaboration with the Meteorology Department of the Ministry of Natural Resources. NEWS collected information on agricultural inputs, especially on the supply of improved seeds and other farm tools before the start of the planting season. NEWS also collected data on farm gate prices of major food commodities from various districts. This information was supplemented with the price information collected

\footnotetext{
1 The regional project was named Early Warning and Food Information System (EWFIS) and was being implemented in seven IGAD member states: Djibouti, Eritrea, Ethiopia, Kenya, Somalia, Sudan and Uganda [15].
} 
through the Market News Service of the Ministry of Trade and Industry. These prices were compared with the rural average ones for changes in the food price levels. NEWS monitored livestock movements and seasonal changes in livestock prices and provided information on the likely outbreak of pests and diseases. In addition, the Nutrition Division in MAAIF would collect and analyze data on child anthropometrics and Body Mass Index for mothers for NEWS database.

The project ended in 1995 due to lack of funding but the unit remained under the coordination of the Directorate of Crop within the Ministry of Agriculture with little facilitation. In 1999, the staff of NEWS was retrenched and the functions of the unit, quite limited until the present, were transferred to the Planning Department, which plans to strengthen it in the near future.

\section{Famine Early Warning Systems (FEWS)}

FEWS carries out vulnerability assessments in the East African region. The project has several bureaus in the region and a home office in Washington, D.C. The Kampala office, which opened in 1996, covers other countries in the great lakes region, e.g., Rwanda and Burundi. The objective of the FEWS project is to provide timely information on impending food shortages that result from disasters like drought, and to warn policy and decisionmakers, along with donors of the need to assess famine threats and plan assistance accordingly. FEWS identifies populations and areas within Uganda where disruptions in food availability and accessibility are likely to have the greatest effect on food security. It also carries out vulnerability assessments to identify populations with risk of food insecurity, taking into consideration food availability and accessibility both at the national and regional levels. FEWS reports contain information on agro-climatic conditions, crop production, pasture and livestock, food stocks and markets.

\section{Evaluating FEWS and NEWS}

In Uganda, there is much interest from the government and international donor agencies to generate food security information and to use the information for planning better policies and intervention programs. However, the contribution of the information generated to decision making processes continues to be weak. Too often, externally funded and designed food security monitoring systems focus primarily on data collection and only secondary attention is given to the use of information for decision making. As a result, the impact of the information produced on decision making has often been negligible. This is further compounded by inadequate co-ordination among information generators and the resulting difficulties in creating effective demand for the food security information from the decision makers. These are but a few of the issues that pose a challenge to the sustainability of food security monitoring systems in Uganda.

Evaluation of food security monitoring systems provides insights into these challenges and helps to re-orient the objectives towards the changing needs for information by policy decision makers. Appendix 1 provides a list of characteristics that have been 
drawn out of the conceptual framework presented in the previous section to evaluate the organizational and operational issues in implementing the monitoring systems. These characteristics are used to compare the impact of information generation by NEWS and FEWS in the process of decision making.

Keeping in mind that the activities of NEWS are currently very limited due to lack of staff and funding - we will concentrate on the originally intended functions of the program to compare the two systems. Although NEWS and FEWS were established to address specific information needs, given the limited infrastructure for data collection and processing, there was little variation in their sources of information. Both the systems addressed information needs on national food self-sufficiency, and attempted to identify the signals that provide early warning of impending food shortages. While the users of information for both these systems were decision makers at the national level, NEWS tended to focus on sectoral and national ministries, and FEWS, the donor community.

Sustainability Issues. It is important to note that both the systems were initiated primarily by donors to meet external needs - by the regional early warning system of IGAD in the case of NEWS, and by USAID in the case of FEWS. The lack of resources to support such systems from within the government puts the sustainability of both systems under constant threat. For instance, due to unavailability of funds for the second phase, NEWS' implementation was left to the government after 1994. This has resulted in a significant cut in the staff employed by NEWS, which renders it quite non-functional and limits its ability to monitor food security. Currently, an agricultural economist is responsible for co-ordinating the functions of the National Early Warning unit, with the help of two statisticians. When the project was initiated, the staff consisted of a multi-disciplinary group of professionals, including agronomists, agricultural economists, and nutritionists along with a support staff consisting of a documenter, a data entry operator, and a secretary. FEWS was established in 1996 and continues to be funded through USAID, with a private consulting firm responsible for its implementation until 2005. An agricultural economist who receives technical support from an expatriate advisor for the project operates the system.

Infrastructure and Capacity Strengthening. Due to its presence within the government system, NEWS uses the existing infrastructure both at the national and at the district levels. FEWS does not have a ready infrastructure for field data collection but hires a team made of government and non-government workers for rapid assessment of food security in the field.

Although a large potential exists for capacity strengthening, NEWS has very limited capacity for analyzing the data collected from the field to design programs and policies. The sustainability of NEWS, thus, largely depends on strengthening and increasing the capacity of the staff to perform analysis and the ability to retain staff. 
The frequency of output differs between the systems. Prior to 1998, NEWS produced a quarterly bulletin compiling information collected over a three-month period. The frequency of this bulletin did not allow it to serve as a timely warning device. NEWS is not producing early warning bulletins currently because of lack of equipment and software to download satellite imagery to support the field data. It does, however, prepare and disseminate seasonal early warning messages to the farming community using field data and weather forecasts. FEWS issues a monthly newsletter that offers more continuous updates on the food security situation. Thus, it has been more successful in creating a high demand for its outputs from donor and international agencies. Conversely, although FEWS is currently able to produce monthly updates, the capacity of doing so beyond the project-funding period is not clear.

Coordination between users and providers of data. A difficulty plaguing both projects is the lack of consultation with the users of the data on the types of information needed from these monitoring systems. Little research has been conducted using the information already gathered and made available.

Despite their assistance in warning governments and donors of impending food crises, there has been a large overlap in the type of data gathered by parallel early warning systems, and the maximum potential for utilizing the information has not been realized. The fundamental challenge in using food security information for planning and policymaking at the national level in Uganda, seems to be the integration of the activities of FEWS with those of NEWS which operates from within the government structure. While both systems tend to use similar sources of information, their location - FEWS in Kampala and NEWS in Entebbe - poses formidable challenges in developing close interaction in information generation and use. Still, in several countries in Southern and Eastern Africa, like Malawi FEWS is physically located in the Ministry of Agriculture and is part of the National Food and Nutrition Information System. This has enabled better division of labor and thereby reducing repetition of outputs - FEWS focusing on the satellite imagery of the NDVI and Cloud Coverage Duration, while NEWS concentrated on production estimates through crop cutting experiments. Along with the household food security and nutrition monitoring surveys conducted at regular intervals, FEWS and NEWS form a complete system of food security monitoring in Malawi.

In Uganda, although there exists willingness by both systems to collaborate, the donorfunded, well-documented FEWS monthly reports have been perceived as a competition, and even a threat to the publication and use of NEWS bulletins by donors. When NEWS and FEWS reports were being produced simultaneously, the distinction in their users NEWS focusing on government authorities, while FEWS emphasizing on donors working on food security issues - gave confusing signals to decisionmakers in the government. This was accentuated by the lack of common ground to discuss and develop a common framework for food security information generation and dissemination in Uganda. It should, nonetheless, be noted that plans are underway to strengthen the 
linkage between NEWS and all the stakeholders involved in food security monitoring activities.

NEWS was originally placed within the Crop Production Section under the Production Department of the Directorate of Extension along with other units such as home economics, animal traction, young farmer union and production. After 1998, NEWS was disassembled and reinstated under the Department of Agricultural Planning of the Ministry of Agriculture. It was thought that the location in the Agricultural Planning Department would enable NEWS to have better access to the monitoring and evaluation units at the district level which are better prepared for collection of information on crop production and other socio-economic characteristics. Nevertheless, its activities on food security monitoring have remained limited mostly due to budgetary limitations, communications constraints with the sources of raw data, coordination difficulties with line ministries, lack of access to remote sensed data, and limited database to foster reliable interpretation and forecasting.

\section{Lessons from Evaluating Food Security Monitoring Systems in Uganda}

Although food security early warning systems have been implemented for the past 20 years in several sub-Saharan countries, only a handful of these countries can be presented as success stories in using early warning information for designing effective interventions in alleviating food insecurity and malnutrition [4, 13]. Even in those countries that have established an operational early warning system, several issues relating to the principles of monitoring food security need to be addressed. Some emerging lessons from the evaluation of the early warning systems in Uganda, along with similar experiences in other sub-Saharan African countries are presented in this section. 


\section{Building Human Capacity}

For successful implementation of early warning systems, having a critical mass of people trained in food security issues from various sectors, including universities and other academic institutions, is a prerequisite. Lack of such capacity to translate the data collected by monitoring systems into policy decisions and to design interventions poses a formidable challenge in all sub-Saharan countries [16]. Strengthening the capacity of subject matter specialists, such as agronomists, livestock specialists, and home economists in national research organizations dealing with food security and nutrition issues, is essential for fostering policy debate and dialogue at the local and national level. This requires a multi-disciplinary approach to capacity strengthening in food security and nutrition policy analysis. Past experiences in such an approach indicate that it is possible to train social scientists in food and nutrition issues, and nutritionists and food scientists in policy and planning methods [17]. This is important, given the overall limited capacity, for designing interventions in the region.

Despite the capacity strengthening efforts of several donors and institutions, the number of experts on food and nutrition monitoring in sub-Saharan Africa has remained very low [16]. In Uganda, even though physical capacity for data collection is adequate, it requires further strengthening to ensure improved quality of output from NEWS. In addition, food security analysis capacity has to be strengthened at decentralized levels [9]. Experiences from Malawi indicate that through constant monitoring and training of nutritionists and social scientists at various levels over a period of three years, it is possible to place necessary capacity in place for information generation and analysis [18].

\section{Ensuring Flexibility of Early Warning Systems}

Information obtained through early warning systems can be used for emergency planning, program design, and policymaking objectives in a wide range of sectors including; agriculture, health, economic planning, social welfare, labor, and famine relief. To meet the diverse information needs and the various objectives of food security interventions, early warning systems should be flexible. Such flexibility does not exist in the currently implemented monitoring systems in Uganda. The case with the food security monitoring systems in Botswana [19], Zambia [20], or Tanzania [21] is similar. For example, the flexibility in Malawi's early warning system enabled a quick transformation of an information system originally designed for policy planning into a system supporting the information needs for drought management as demonstrated by the recent efforts to prevent famine in Southern Africa [22].

\section{The Need for a Multi-sectoral Committee on Food Security and Nutrition}

The immediate need in sub-Saharan Africa is the establishment of multi-sectoral committees on food security and nutrition that involve agriculture, health, transport, trade and industry, natural resources ministries, as well as academic and research institutions. Such committees may also include donor representatives as observers. Although various 
sectoral ministries could implement early warning systems to meet their planning and policy making objectives, it is important to have a focal office at the national level to bring together the outputs of the various systems operating in a country. Without a central committee to coordinate the activities of early warning systems, messages from different sources can lead to confusion and delay effective response [8]. For example, during the periods of drought management in Malawi, the Disaster Preparedness Committee, coordinated by the Office of the President and Cabinet, acted as the decision making group and was responsible for dissemination of information to donors and other international organizations. This substantially reduced the duplication of informationgathering efforts by several independent and non-governmental organizations [22].

Experience from other sub-Saharan African countries shows that when food and nutrition information systems are placed at higher levels such as the Office of the President or the prime minister, developing an ongoing advocacy campaign to promote a common understanding of food security and nutrition issues, as well as keeping them at the forefront of the policy dialogue becomes much easier [23]. Unfortunately, in several countries, including Kenya, Zambia, Zimbabwe, and Swaziland, the efforts to organize information generation and use have been hamstrung by bureaucratic barriers against coming together through multi-sectoral food and nutrition committees [6].

\section{Strengthening Infrastructure for Data Collection}

One of the major constraints in developing comprehensive early warning systems in subSaharan Africa has been the limited infrastructure to collect and process the data from the field. While such an infrastructure exists in Uganda, it is poorly developed to meet all data generation needs. In countries with a well-developed network of data-collection systems, it is generally suggested that the existing infrastructure should be used effectively [24]. In countries where there are no organized data-collection systems for food-security monitoring, such as Eritrea and Namibia [25], it may be necessary to create new infrastructure. Elsewhere, it is possible to combine the existing but poorly organized structures and reorient them towards specific goals of food security monitoring. In Uganda, as in Malawi, Botswana, and Kenya, the use of data-collection institutions that were in place for the collection of information in farm management and agricultural surveys could make possible cost-effective food security monitoring systems [10].

\section{Data for Who?}

Collecting and analyzing information will not by itself lead to successful policy implementation. According to Habicht [2000] all evaluations should start with the question, "Who will use the information and for what purpose?" The lack of continuous assessment of the user needs rendered the output of NEWS "data-driven" and thus, less useful to the policy makers in Uganda. One way of preventing the efforts spent on data collection and analysis from becoming futile is to involve the decision makers in the generation of information. Another option is to perform a user needs assessment [27]. For example, during the 1991 to 1992 drought in Malawi, the designers of the monitoring 
system constantly evaluated the information needs for drought management planning by working closely with the Disaster Preparedness Committee. This increased user participation in the monitoring system and reduced the probability of its becoming a process-driven system [22]. Another lesson learned from Namibia and Zambia is that reducing the number of data variables will increase the use of information in decision making [20].

\section{Timeliness of Data Generated}

The early warning system established in Uganda has the potential of generating situation analysis reports within four to six weeks from the time of data collection if the human capacity of NEWS is improved with additional resources for field operations. This is possible in Malawi, because of the trained human capacity and resources for data processing, analysis, and preparation of food security working papers at the district level [28].

In addition, the availability of timely information for making appropriate decisions and the quality of information presented to the decisionmakers play an important role in strengthening the information-action linkages. For instance, the quarterly nature of NEWS bulletins in Uganda make them less timely for meeting immediate information needs. The time gaps between collection of data and analysis, and between analysis and reporting, have been so wide in the past that when the information is given to the decision makers, it is too late for them to make effective use of it. To minimize this time lag, it is essential to decentralize the data processing and analysis systems. In doing so, attention should be paid to developing appropriate but flexible computer data processing systems at the district levels.

\section{Analyzing and Reporting Data}

One of the major criticisms of the currently operating monitoring systems in sub-Saharan Africa is that of the large volume of data that is collected, only few are analyzed, and even fewer are reported from the subset that have been analyzed. Another issue to focus on is the presentation of the material. The analyses should strive to be as transparent as possible and clearly communicate to policymakers through different media outlets, including printed press, radio, town meetings, and computer networks [27]. For instance, one of the reasons identified for the recent food shortage experienced in Malawi is the failure by the media to identify the government and donors in time to avert the crisis [29].

\section{Livelihoods Approach}

Prior to the famine of 2002 in Malawi, two different systems predicting the situation of food security in the country reached different conclusions. While an assessment by FEWSNET Malawi - a sister program of the FEWS network in Uganda - did not clearly identify the famine, another assessment by Save the Children-UK (SC-UK), predicted 
that barring lower prices of maize by 2002 was inevitable. Why was the SC-UK able to foresee the crisis? As pointed out by Seaman [2], this was possible because SC-UK, through a vulnerability analysis [using the Household Economy Approach (HEA)], was able to gather information on people's livelihoods in an accurate and geographically disaggregated fashion. The FEWSNET assessment, on the other hand, despite identifying a potential problem, was not able to break down aggregate food supply to the level of household access, to food.

Although, NEWS in Uganda is helpful in gathering information at the district level, it falls short of providing information on household food security and on vulnerable population groups. Given that there is food self-sufficiency at the national level, at least during the years of normal rainfall, and that the major food insecurity threats are at the household level, there is a need to go one step further to the household level to collect information and formulate programs and policies to mitigate the household food insecurity.

Malawi was the first country in southern Africa to establish a food security and nutrition monitoring system at the household level [28]. Based on lessons learnt from the Malawi experience [30], a Regional Food Security and Nutrition Information System has been established by the Southern Africa Development Community (SADC) in selected member countries (Mozambique, Swaziland and Zimbabwe) with a focus on identifying probable causes of household food insecurity [31].

There has been a recent shift in early warning systems towards using livelihood approaches similar to that of SC-UK's in identifying impending food-related disasters. For instance, the Famine Early Warning Systems Network (FEWSNET) now employs "... food economy principles and techniques to ensure a quantifiable, and therefore comparable output from its livelihood baselines. These baselines are used as the reference point against which to judge the effects of current shocks." [32] To do so, FEWSNET has started working in collaboration with organizations like Save the Children and OXFAM. Even though this shift towards utilizing livelihood approach deserves applause, such baseline reports are limited to only a few countries and subregions and FEWSNET does not currently have the capacity to start using these reports in actual food and nutrition monitoring. Also, the decision to establish Food Insecurity and Vulnerability Information and Mapping Systems (FIVIMS) following the World Food Summit of 1996, is promising for the identification of food insecurity and malnutrition at the household level [27]. 


\section{CONCLUSION}

Recently, there has been considerable interest among planners and policy makers in identifying cost-effective and time-efficient approaches to monitoring the food security status of developing-country households. Enhancing the effectiveness of food security and nutrition monitoring systems requires the use of recent innovations in data collection, processing, analysis and interpretation by planners, designers and field staff. This can be made possible through the evaluation of monitoring systems operated for various objectives and under different circumstances. The outcome of such evaluations should be constantly reinforced by additional lessons from the implementation of food security and nutrition monitoring systems from other countries. The evaluation of NEWS and FEWS in Uganda, presented in this paper, is an attempt in this direction.

The focus on the two programs has brought to light some important issues that need to be addressed in food and nutrition monitoring systems. These include the need for establishing multi-sectoral committees on food security and nutrition issues in Africa, building human capacity in food security, ensuring the flexibility of early warning systems so that they can be used in emergency planning, program design, and policy making in various sectors, strengthening the infrastructure for data collection, identifying and acknowledging the users of the data, and generating timely information that will be analyzed and reported accurately.

Frequent evaluation of the methods and the systems of monitoring food security is essential for generating continued interest by decision-makers. This will also provide an opportunity for the existing food security monitoring systems to evolve into those that encompass spheres of livelihood security and bring preventive and proactive solutions rather than curative approaches [13]. A majority of food security monitoring systems continues to be based on macro-level information and operated at the national level. Future challenges in addressing household food security will require devolution of the process of food security monitoring and intervention systems to decentralized levels. In meeting these challenges, the role of continued evaluation of food security monitoring systems for their impact on food security decisionmaking cannot be overemphasized. 


\section{APPENDIX 1}

CHARACTERISTICS FOR EVALUATION AND COMPARISON OF NEWS AND FEWS IN UGANDA

\begin{tabular}{|c|c|c|}
\hline Characteristics & $\begin{array}{c}\text { National Early Warning System } \\
\text { (NEWS) }\end{array}$ & $\begin{array}{c}\text { Famine Early Warning System } \\
\text { (FEWS) }\end{array}$ \\
\hline $\begin{array}{l}\text { Purpose of } \\
\text { monitoring } \\
\text { system }\end{array}$ & $\begin{array}{l}\text { Timely warning of impending food } \\
\text { shortages }\end{array}$ & $\begin{array}{l}\text { Early warning of famine and food } \\
\text { needs to prevent food-related } \\
\text { disasters }\end{array}$ \\
\hline Scope & $\begin{array}{l}\text { Oriented towards food security at the } \\
\text { national level }\end{array}$ & Famine-oriented \\
\hline $\begin{array}{l}\text { Level of } \\
\text { operation }\end{array}$ & $\begin{array}{l}\text { National/macro level and centralized } \\
\text { with support from district level data } \\
\text { collection systems }\end{array}$ & $\begin{array}{l}\text { National/macro level and centralized } \\
\text { operation }\end{array}$ \\
\hline $\begin{array}{l}\text { Level of } \\
\text { information use }\end{array}$ & $\begin{array}{l}\text { National level - sectoral ministries } \\
\text { in governments and some non- } \\
\text { governmental organizations }\end{array}$ & $\begin{array}{l}\text { National level - government and } \\
\text { non-governmental agencies, } \\
\text { including donors dealing with food } \\
\text { security issues }\end{array}$ \\
\hline $\begin{array}{l}\text { Determinants of } \\
\text { food security } \\
\text { monitored }\end{array}$ & $\begin{array}{l}\text { Food production and food availability } \\
\text { in all parts of the country }\end{array}$ & $\begin{array}{l}\text { Food production and food } \\
\text { availability in selected and } \\
\text { vulnerable parts of the country }\end{array}$ \\
\hline $\begin{array}{l}\text { Types of data } \\
\text { collected }\end{array}$ & $\begin{array}{l}\text { Rainfall, crop growing conditions, } \\
\text { food prices, agricultural input } \\
\text { situation, incidence of pests and } \\
\text { diseases, livestock and pasture } \\
\text { conditions, and food situation in } \\
\text { chronically food insecure areas }\end{array}$ & $\begin{array}{l}\text { Meteorological images, market } \\
\text { prices, normalized D vegetation, } \\
\text { index and input use data }\end{array}$ \\
\hline Sources of data & $\begin{array}{l}\text { Ministry of Trade and Industry, } \\
\text { Meteorological Department, Ministry } \\
\text { of Natural Resources, District Level } \\
\text { Crop Assessment Information from } \\
\text { District Extension Officers }\end{array}$ & $\begin{array}{l}\text { Satellite imagery, sectoral ministries } \\
\text { such as trade and industry, natural } \\
\text { resources, and agriculture; district } \\
\text { level information through rapid } \\
\text { assessment for convergence of } \\
\text { evidence }\end{array}$ \\
\hline $\begin{array}{l}\text { Overall } \\
\text { approach }\end{array}$ & $\begin{array}{l}\text { Major focus is on compilation of data } \\
\text { from various sources and hence tends }\end{array}$ & $\begin{array}{l}\text { In addition to the collection of data } \\
\text { from various sources, it endeavors to }\end{array}$ \\
\hline
\end{tabular}




\begin{tabular}{|c|c|c|}
\hline Characteristics & $\begin{array}{c}\text { National Early Warning System } \\
\text { (NEWS) }\end{array}$ & $\begin{array}{c}\text { Famine Early Warning System } \\
\text { (FEWS) }\end{array}$ \\
\hline & to be data-centered & be information-centered \\
\hline Units of analysis & $\begin{array}{l}\text { Geographic units demarcated by } \\
\text { districts }\end{array}$ & $\begin{array}{l}\text { Geographic units demarcated by } \\
\text { districts and some analysis of } \\
\text { vulnerable groups }\end{array}$ \\
\hline Nature of output & $\begin{array}{l}\text { Used to publish a quarterly bulletin in } \\
\text { March, June, October and December } \\
\text { of every year containing descriptive } \\
\text { tables but has not been doing so since } \\
1998 \text { due to lack of funding }\end{array}$ & $\begin{array}{l}\text { Monthly report indicating agro- } \\
\text { climatic conditions, crop production, } \\
\text { food stocks, flow and market } \\
\text { conditions and trends on prices of } \\
\text { food. Each report has special } \\
\text { emphasis on issues of thematic } \\
\text { importance }\end{array}$ \\
\hline $\begin{array}{l}\text { Users of } \\
\text { information }\end{array}$ & $\begin{array}{l}\text { Decision-making authorities in the } \\
\text { ministries of agriculture, trade and } \\
\text { industry and districts that need } \\
\text { attention. }\end{array}$ & $\begin{array}{l}\text { Decision-makers in selected sectoral } \\
\text { ministries, donor agencies, NGOs } \\
\text { and few private traders, district level } \\
\text { authorities who were helpful in data } \\
\text { collection. }\end{array}$ \\
\hline $\begin{array}{l}\text { Linkages to } \\
\text { other sectors }\end{array}$ & $\begin{array}{l}\text { Limited linkages with health, trade } \\
\text { and industry, transportation, local } \\
\text { administration, natural resources. }\end{array}$ & $\begin{array}{l}\text { Limited linkages with natural } \\
\text { resources, local administration, trade } \\
\text { and industry, labor and social } \\
\text { affairs. }\end{array}$ \\
\hline $\begin{array}{l}\text { Linkages to } \\
\text { presidential } \\
\text { decision-making }\end{array}$ & $\begin{array}{l}\text { Limited linkages through the Minister } \\
\text { of Agriculture who is also the Vice- } \\
\text { president of the country. }\end{array}$ & $\begin{array}{l}\text { Limited linkages through other } \\
\text { projects also funded by USAID such } \\
\text { as IDEA and linkages to Export } \\
\text { Policy Analysis Unit of the Ministry } \\
\text { of Finance and Economic Planning. }\end{array}$ \\
\hline $\begin{array}{l}\text { Linkages to the } \\
\text { region }\end{array}$ & $\begin{array}{l}\text { The unit was established with } \\
\text { technical and financial support from } \\
\text { Inter-Governmental Authority on } \\
\text { Development's (IGAD) Regional } \\
\text { Early Warning and Food Information } \\
\text { System. Quarterly bulletins were sent } \\
\text { to IGAD for production of regional } \\
\text { bulletins. IGAD continues to provide } \\
\text { technical linkages to other countries in } \\
\text { the region. }\end{array}$ & $\begin{array}{l}\text { Has linkages to Regional Famine } \\
\text { Early Warning System and FEWS in } \\
\text { other countries in the Sahalian } \\
\text { region. Funded by USAID and } \\
\text { managed by a US-based private } \\
\text { consulting firm. }\end{array}$ \\
\hline
\end{tabular}


Characteristics National Early Warning System (NEWS)

Nature of

personnel

Infrastructure for information generation
An agricultural economist and two statisticians.

Uses existing infrastructure at national and district levels. No additional personnel have been hired other than those employed by NEWS unit.
Famine Early Warning System (FEWS)
Capacity for analysis

Capacity for planning and policymaking

Timeliness in data processing

Response system National food self-sufficiency being

Information and action linkages the goal, response system is triggered towards food production, orientation with seeds, and other inputs supplied to avert major disasters with medium to longer term time frame.

Limited capacity exists for analysis of data beyond basic description of variables on which data have been collected. Large potential exists for capacity strengthening.

Capacity is limited to information gathering and compilation - no capacity exists to link information to planning and policymaking.

Reports were produced once every three months when first founded but no reports produced currently.

Limited linkage to decision-making and action although decision-makers are provided with information.
Implemented by an agricultural economist with technical support from an expatriate technical advisor.

Does not have infrastructure for field data collection although uses a team of staff hired from the government as and when the need arises for rapid assessment. Uses informal arrangements with other donor projects to collect and compile information.

Capacity exists for the analysis needed to meet the objectives of the FEWS.

The output of FEWS is not intended for planning or policy analysis.

Early Warning reports are prepared on a monthly basis to meet the continuous information needs from various donor agencies.

Given the proximity to the donor and international organizations, the response system seems to be foodaid oriented with seasonal or short time frames.

Better linkage to action, particularly through donors, such as USAID, WFP, and other projects involved in solving food security issues. 


\section{Characteristics National Early Warning System $\quad$ Famine Early Warning System (NEWS)

Creation of a demand for information

Accountability of decisionmakers

National focal point for information dissemination

Cost of operation of monitoring

Nature and extent of decentralization
Except for a few donor agencies, such as FAO and Regional Early Warning Unit in IGAD, it was not successful in creating local demand for its information bulletins.

Not likely to generate accountability for information use by decisionmakers.

No national focal point for clearing of information exists for dissemination of outputs from NEWS. Even within the Ministry there exists no organized way of using information from NEWS for intervention.

Data gathering conducted as part of the regular job of staff involved but there is shortage of staff and lack of capacity; resource limitations for travel to organize and supervise data collection reduces the timeliness of early warning.

Information generation is decentralized and fits well with the decentralization of administration to districts that have been promoted in Uganda. However, decentralization in the use of information to solve food insecurity issues remain a question.
Has been successful in creating demand for the monthly reports, particularly among NGOs and donor agencies.

Due to its high-profile nature and its financial support from USAID, it finds ready users among donor agencies. However, it is in no position to make decision-makers either in government or outside accountable for action.

Does not operate closely with any national committees. The efforts of FEWS will be more fruitful if it collaborated with a national focal point in the Ministry of Finance or in the President's Office.

Costs of FEWS funded externally although the cost of personnel is as much as four times higher compared to national system with similar potential for output.

By design, there is no room for decentralization except for occasional collaboration with district level authorities. More of a decentralized approach recently, due to efforts to involve a livelihoodbased approach to food insecurity. 
Flexibility to change

Mobility

Sustainability of monitoring system
NEWS provides opportunity for changing the contents of monitoring at the district level if it was given adequate support and training to staff at those levels.

Although, it covers the whole country geographically, due to budgetary restrictions, mobility of NEWS' staff is limited.

NEWS has potential to be sustainable given increased commitment from the government for food security issues. It needs better access to resources and increased capacity for analysis and linking analysis to action.
FEWS, given the nature and extent of information collected, tends to be less flexible for changing. There is a recent move towards applying a livelihoods lens to food security monitoring.

FEWS is better mobile geographically as well as between various groups of vulnerable populations.

The project-oriented and donororganized and funded nature of the efforts without linkage to continuity threatens sustainability of FEWS. The program, however, has been active in Africa for a couple of decades which is promising for the continuation of funding in the future. 


\section{REFERENCES}

1. Deng BL Famine in the Sudan: causes, preparedness and response: a political, social, and economic analysis of the 1998 Bahr el Ghazal famine, IDS Discussion Paper 369, 1999.

2. Seaman J Rethinking early warning systems, humanitarian exchange, 2002; 22:1013, http://www.odihpn.org/pdfbin/newsletter022.pdf.

3. Habicht JP and P Pinstrup-Andersen Principles of nutritional surveillance. Pew/Cornell Lecture Series on Food and Nutrition Policy, Cornell University, Ithaca, New York. 1990.

4. Buchanan-Smith M, Davies $\mathbf{S}$ and $\mathbf{R}$ Lambert A Guide to famine early warning and food information systems in the Sahel and Horn of Africa. Research Report No. 21, Vol. 2. Institute of Development Studies, University of Sussex, 1991.

5. Davies S, Buchanan-Smith $M$ and $\mathbf{R}$ Lambert Early warning in the Sahel and Horn of Africa: the state of the art: A review of the literature. Research Report No. 20, Vol. 1. Institute of Development Studies, University of Sussex, 1991.

6. Quinn VJ and E Kennedy Food security and nutrition monitoring systems in Africa, Food Policy, 1994;19:234-254.

7. Habicht JP Nutritional surveillance in China: results of user survey. Mimeo, Cornell Food and Nutrition Policy Program, Ithaca, New York, 1991.

8. Report for the Second International Early Warning Conference (EWC II). Synthesis of the findings of the early warning regional consultations in Africa, Asia, the American Hemisphere and Europe. Bonn, Germany, October 16-18, 2003.

9. IDNDR. International Decade for Natural Disaster Reduction. Guiding principles for effective early warning, The Convenors of the International Expert Groups on Early Warning of the Secretariat of the International Decade for Natural Disaster Reduction IDNDR Early Warning Program, Geneva, October 1997.

10. Babu SC and GB Mthindi Costs and benefits of informed food policy decisions - a case study of food security and nutrition monitoring in Malawi, Quarterly Journal of International Agriculture, 1995;34-3:292-308.

11. Benfield Creig Hazard Research Center Center for Research on the Epidemiology of Disasters and Actionaid, 2002, Development at risk: The brief for the World Summit on Sustainable Development, Johannesburg, South Africa, 26 August- 4 September, 2002.

12. Pelletier D 1993 Towards a UNICEF nutrition information strategy: Report of a meeting. Nutrition Section and Evaluation and Research Office, UNICEF New York, May 1993.

13. Davies S Adaptable livelihoods: coping with food insecurity in the Malian Sahel Institute of Development Studies, University of Sussex, 1996.

14. Babu SC and B Chaura Facing donor missions with informed policy decisions - lessons from food security and nutrition monitoring in Malawi," Africa Development, 1997:22. 
15. IGAD Inter-Governmental Authority on Development. Assistance for strengthening the national food information system in Uganda - project document. Inter-Governmental Authority on Development, Djibouti, 1994.

16. Babu SC, Mthindi GB and D Ng'ong'ola Developing decentralized capacity for development policy analysis - lessons from food security and nutrition monitoring in Malawi. African Development Review, 1996;8:127-145.

17. Babu SC Rethinking training in food policy analysis: how relevant is it to policy reforms? Food Policy, 1997;22:1-9.

18. Babu SC Multi-disciplinary capacity strengthening for food security and nutrition policy analysis - lessons from Malawi. Food and Nutrition Bulletin forthcoming, 1997.

19. Belbase $\mathbf{K}$ and $\mathbf{R}$ Morgan Food security and nutrition monitoring for drought relief management. Food Policy. 1994;19:285-300.

20. Eele D Indicators for food security and nutrition monitoring. Food Policy. 1994;19:314-328.

21. Pelletier $\mathbf{D}$ and $\mathbf{U}$ Jonsson The use of information in the Iringa nutrition program: some global lessons for nutrition surveillance. Food Policy, 1994;19:301-313.

22. Babu SC and E Chapasuka Mitigating the effects of drought through food security and nutrition monitoring: lessons from Malawi. Food and Nutrition Bulletin, 1997;18:71-83.

23. Quinn VJ A history of the politics of food and nutrition in Malawi: the context for food and nutrition surveillance. Food Policy, 1994;19:255-271.

24. Arnauld J, Alarcón JA and MDC Immink Food security and food and nutritional surveillance in Central America: the need for functional approaches," Food and Nutrition Bulletin, 1990;12:26-33.

25. Botes A Household food security and nutritional surveillance in Namibia: the methodology and its use in development and policy interventions. Paper presented at the Southern Africa Regional Conference on Household Food Security and Nutrition Monitoring for Development Planning and Policy Interventions, SADCC/UNICEF/USAID/UNIFEM/CFNPP, Mangochi, Malawi, 7-9 April 1992.

26. Habicht JP Evaluation and monitoring: Who needs what information and why do they need it? Food and Nutrition Bulletin 2000;211:87-90.

27. IFAD. International Fund for Agricultural Development. Guidelines for National FIVIMS: Background and Principles, Second Meeting of the Inter-agency Working Group (IAWG) on Food Insecurity and Vulnerability Information and Mapping Systems (FIVIMS), April 15-17, 1998.

28. Babu SC and GB Mthindi Developing decentralized capacity for disaster prevention: lessons from food security and nutrition monitoring in Malawi," Disasters 1995;192:127-139.

29. SARPN. Southern African Regional Poverty Network, Poverty Brief, March 2003. 
30. Babu SC Improved policies through food security and nutrition monitoring. Food Policy. 1992;5:384-386.

31. Mugwara R Linking relief with development in Southern Africa: A SADC perspective on the 1991/92 drought emergency, IDS Bulletin, 1994;25:92-95.

32. FEWS NET. Famine Early Warning Systems Network http://www.fews.net/livelihoods/about.cfm.

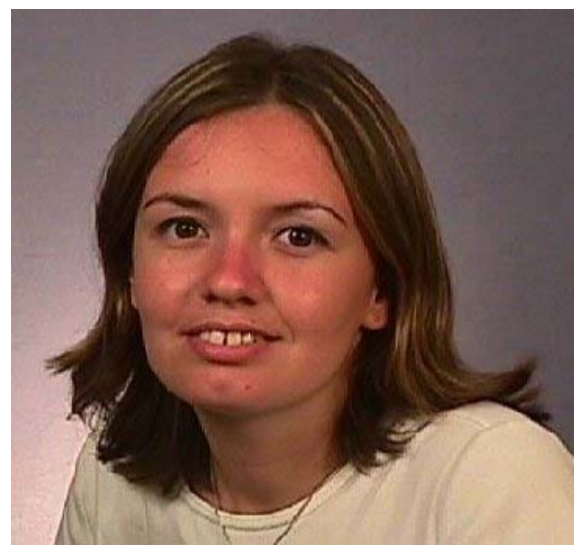

Ayca ERgeneman 